\title{
NEGATIVE IMPACT OF SURGICAL SMOKE
}

\author{
M J. Hedau \\ Department of Electronics \\ Shivaji Science College, Nagpur, India \\ E-mail:- maheshhedau1@gmail.com
}

\begin{abstract}
:
Electrosurgeon performing surgeries using electrosurgical unit or surgical diathermy machines are routinely exposed to surgical smoke, plume and aerosols produced by instruments used to dissect tissue and provide haemeostasis. The safety of the patient and its importance during surgeries are well recognized however less emphasis is placed upon the safety of the surgeon and his/her team. Use of Electro-surgical techniques has expanded greatly in recent years, depending on the nature of the surgical site and the length of the procedure; operation staffs are exposed to smoke for periods ranging from a minute or so, repeated infrequently, to several hours a day. This review discusses the adverse effects of surgical smoke and cautious the surgeons against the risks involved during such surgeries.
\end{abstract}

Keywords: Diathermy, surgical smoke, risks, safety.

\section{INTRODUCTION:}

Electrosurgeons who are performing various types of surgery using surgical diathermy technique or electrosurgical unit are knowingly or unknowingly exposed to harmful gaseous substances which can make them vulnerable to various deadly diseases [1].This gaseous substance is commonly called as surgical smoke. Surgical smoke has become a part of the patient care environment wherever surgical or invasive procedures are performed. It is known by variety of names, such as cutery smoke, diathermy plume, plume, smoke-plume, aerosols, bioaerosols, vapour and air contaminants, it can be seen and also smelled [2].

Surgical diathermy is an invaluable facility widely used in operating theatre [3]. It has become an indispensable tool to the modern surgeons and is used in the majority of surgical procedures. Though this technique has proved to be the boon for surgeons by eliminating the use of conventional cutting tools and blood loss, the technique has showed the signs of flaws when it became hazardous for the person itself who wants to save the life of other person i.e. surgeons themselves and also the team assisting them during surgeries.
Surgical diathermy incorporates the use of different electrical waveforms, current is made to pass through tissues and the resistance encountered produces heat, this heat causes intracellular water to boil, the cell explode and tissues divide, for coagulation current develops less heat, causing drying and thus coagulation, both these process produces a varying degree of

plume or surgical smoke[4]. Perioperative professionals and patients are routinely exposed to surgical smoke produced by instruments used to dissect tissue and provide haemostasis. Anything that produces heat can produce smoke or aerosols. Smoke and aerosol-generating procedures can pose health risks [5].

Surgical smoke generated through such processes possesses a significant biochemical hazard and has shown to be as mutagenic as cigarette smoke [6]. In an animal model, it was found that the mutagenic potency of condensates from $1 \mathrm{~g}$ of electrocautery destroyed tissue through ablation was equivalent of smoking six unfiltered cigarettes [7].

\section{ORIGIN OFSURGICALSMOKE:}


Surgical smoke is produced by any technique that produces heat and comes in contact with body [5]. Various techniques used in operating rooms such as electrosurgery units, lasers, ultrasonic devices, high-speed drills, burrs and saws produces heat, which allows the surgeon to achieve the desired tissue effect. The most common device used is the electrosurgery unit. Electrosurgery uses high-frequency current to cut and coagulate tissue. The disruption releases the cellular fluid as steam and spews the cell contents into the air forming surgical smoke plume [8].

Lasers are the second most common heat-producing device. Lasers produce high heat that boils and explodes the cells. This cellular vaporization releases steam and cell contents [9]. When the particulate matter of both laser and electrosurgical smoke are compared they are very similar. Thus smoke evacuation facility for electrosurgery units and for lasers should be same [10].

\section{SURGICAL SMOKE COMPONENTS:}

Surgical smoke is made up of $95 \%$ water or steam and $5 \%$ cellular debris in the form of particulate material. The particulate matter is composed of chemicals, blood and tissue particles, viruses, and bacteria [11].It is the effects of these chemicals and the potential risk from airborne cellular debris which has raised concern about the hazard of surgical smoke to staff and patients [12].

A long list of surgical smoke contents have been identified in surgical smoke. Two chemicals of the concern are acrylonitrile and hydrogen cyanide. Acrylonitrile is a volatile, colourless chemical that can be absorbed through the skin and lungs. Acrylonitrile liberates hydrogen cyanide. Hydrogen cyanide is toxic, colourless and can also be absorbed into the lungs, through the skin and via the gastrointestinal tract [13].

\section{SMOKE PARTICLE SIZE:}

Each type of heat-producingdevice produces a different size particle in itssurgical smoke or plume. The smallerthe particle size, the further it can travel. Thiscan affect nonscrubbed members of the surgical team such as circulating nurse, anesthesia care provider during a procedure as well as teammembers who are scrubbed [14].Particles that remain airborne aresmaller than 100 micrometers in diameter. Particlesthat are 5 micrometers or larger are depositedon the walls of the nose, pharynx, trachea,and bronchus. Particles that are smaller than2 micrometers in size are deposited in the bronchiolesand alveoli, which is the gasexchangeregion of the lungs [15]. Viruses are the smallest insize, ranging from about 0.01 to 0.3 micrometers [16].

\section{PREVENTIVE MEASURES:}

The best defense against surgical smoke is to use available tools and knowledge to minimize exposure to surgical smoke, until there are regulations that reduce the occupational hazard of surgical smoke and to become an expert in what is being done [17].

There are number of ways to minimise risks of surgical smoke exposure [6].Ventilation system can be used to capture and extract bacteria and dust particles existing in all operating theatre. Specialised mechanical surgical smoke evacuating and filtration systems that uses high-powered suction, filtering the majority of contaminants and returning filtered air to the operating theatre can provide some degree of protection. To some extend standard surgical masks or ultra- filtering masks can also be used [6].

\section{ADVERSE EFFECTS OF SMOKE:}

(i) Eyes Irritation: Electrocautery smoke has been found to contain significant amount of chemical that constitute irritants to the eye [18] [19].

(ii) Hypoxic stress: The burning of protein and lipids during electro surgery liberates by products which cause acute inflammation of the airways [20]. 
(iii)Infection Transmission: Viruses and other infectious agents are transferred from patient to surgeon or vice versa [21].

(iv)Gene Mutation: Benzene, a known carcinogen has been identified in significant quantity in the smoke; this is the contributory factor of mutagenic effect in electrocautery smoke [18].

\section{CONCLUSION:}

An attempt has been made to highlight the potential risk faced by electrosurgeons and its staff while performing electrosurgery. The recommendations provided in this review serve as an evidence-based means of reducing surgeon's vulnerability in the operating theater.

\section{REFERENCES:}

Watson A.B., Lounghman J. The surgical diathermy; principles of operation and safe use. Anaesth. Intensive care. 1978 Nov; 6(4): 310-21.

Ulmer BC 2008 The hazards of surgical smoke AORN Journal 87(4) 721-738

Makama G.J. Makama G.J. Ameh E A. Hazards of surgical diathermy. Niger. J. Med. 2007;16:295e300

Sudhindra T.V., Joseph A., Hacking C.J., Haray P.N. Are surgeons aware of the dangers of diathermy Ann R Coll. Surg, Eng. 12000; 82: 31-2.

Brenda C. Ulmer, RN, MN, CNOR. The Hazards of Surgical Smoke AORN, Inc, 2008APRIL 2008, VOL 87, NO 4 • AORN JOURNAL.

Hill D.S., O’Neill J.K., Powell R.J., Oliver DW. Surgical smoke - a health hazard in the operating theatre: a study to quantify exposure and a survey of the use of smoke extractor systems in UK plastic surgery units. J. Plast. Reconstr. Aesthet. Surg. 2012; 65:911e6.

Tomita Y, Mihashi S, Nagata K, Ueda S, Fujiki M, Hirano M, et al. Mutagenicity of smoke condensates induced by $\mathrm{CO} 2$-laser irradiation and electrocauterization. Mutat Res 1981; 89:145e9.
Anderson K 2004 Safe use of lasers in the operating room AORNJournal79 (1) $171-188$

Emergency Care Research Institute 1990 ESU smoke - should it be evacuated? Health Devices 19 (1) 12.

Gonzalez-Bayón L, S,Ortega-PerézG. Safety considerations for operating room personnel during hyperthermic intraoperative APRIL 2008, VOL 87, NO 4 intraperitoneal chemotherapy perfusion.

Hersman C, Baty D, Willis RG, Cushieri A. Chemical composition of smoke produced by high frequency electrosurgery in a closed gaseous environment. SurgEndosc1998; 12: 1017-9.Ann R CollSurgEng12007; 89: 162-165.

Barrett WL, Garber SM 2004 Surgical smoke: a review of the literature Business Briefing, Global Surgery 1-7.

Karoo RO, Whitaker IS, Offer G, Shape DT. Surgical smoke without fire: the risks to the plastic surgeon. PlastReconstrSurg.2004; 114(6):16581660.AORN JOURNAL APRIL 2008, VOL 87, NO 4.

Taravella MJ, Viego J, Luiszer F, et al. Respirable particles in the excimer laser plume. $\mathrm{J}$ Cataract RefractSurg.2001; 27(4):604607.AORN JOURNAL APRIL 2008, VOL $87, \mathrm{NO} 4$.

Dykes CN. Is it safe to allow smoke in our operating room? Today's Surg Nurse. 1999;21(2):15-21, 38-39. AORN JOURNAL APRIL 2008, VOL 87, NO 4.

Dawes BG 2000 Stop smoke campaign begins with you AORN Journal72 (5) 768-770.

Sagar PM, Meagher A, Sobezak S, Wolf BC. Chemical composition and potential hazards of electrocautery smokes $\mathrm{Br} . \mathrm{j}$ surg. 1996: 83:1792.

www.afpp.org.uk 
Pillinger SH, Delbridge L, Lewis DR. Randomized clinical trial of suction vs. standard clearance of diathermy plume. $\mathrm{Br} \mathrm{J}$ surg. 2003; 90:1068-1071

Voyles CR, Tucker RD. Education and engineering solutions for potential problems with laparoscopic monopolar electro surgery. Am j surg 1992; 164:57-62.

BaggishMS,Polesz BJ, Joret D, Williamson P, Pefal A. Presence of human immunodefiecey virus DNA in laser smoke. Laser surg. Med. 1991; 11:197203.

$* * * * * * * *$ 